\title{
Responses to COVID-19 in the Context of Quality Assurance, Quality Improvement and Scholarship Requirements for Curricula
}

\author{
Tina Acuña and Jo-Anne Kelder \\ Corresponding authors: Tina Acuña (tina.acuna@utas.edu.au), Jo-Anne Kelder (jo.kelder@utas.edu.au) \\ College of Sciences and Engineering, University of Tasmania, Hobart Tasmania 7000, Australia
}

Keywords: curriculum evaluation framework, STEM curricula, scholarship

\begin{abstract}
Our Curriculum Evaluation and Research-STEM Teaching Fellowship embeds leadership for active engagement in scholarship within teaching teams. It is a response to Higher Education Standards Framework (HESF) minimum requirements for continuous evaluation informing ongoing curriculum transformation, specifically the TEQSA Guidance Note: Scholarship (2018). The Fellowship contextualised the existing 'Curriculum Evaluation Research (CER) framework' (Kelder \& Carr, 2017) for the specific characteristics of STEM degrees and teaching teams. The framework supports team-based planning and doing activities that are aligned with institutional structures, processes and governance instruments, so that scholarship can be made visible, monitored, measured, met and reported at the level of degree curriculum. Here we describe fellowship outcomes in the context of responses to COVID-19 using a case study at the University of Tasmania.
\end{abstract}

\section{Introduction}

In mid-2019 we commenced the inaugural Australian Council of Deans of Science (ACDS) Teaching Fellowship. The Fellowship project was proposed as a response to the minimum requirements for scholarship, set out in the Australian Higher Education Standards Framework (HESF), and the Tertiary Education Quality and Standards Agency's (TEQSA) explanatory Guidance Note: Scholarship (TEQSA, 2018), hereafter Guidance Note.

The Guidance Note states that 'the intent of the Standards is that scholarship that is claimed to inform teaching (or supervision) must have a demonstrable relevance to the course being taught, including scholarship relating to the process of teaching and learning in itself.' However, changes to national learning and teaching awards and grants signals that such scholarship is in practice an undervalued and largely invisible activity. Anecdotal evidence from discussion with colleagues suggests that scholarship may be neglected altogether by academics and management.

In STEM, prioritisation of disciplinary research and lack of capacity/expertise in research approaches that are more common to the humanities and education represent substantial barriers to scholarship in learning and teaching (Kelly et al., 2012). In this context, it is imperative to identify mechanisms to engage and reward the broad cohort of STEM academics to engage in scholarship of teaching and learning (SoTL). 
Building on research that developed and disseminated the Curriculum Evaluation and Research (CER) framework (Kelder \& Carr, 2016), we appreciated that the issues of time (low availability) and workload (high requirements) were significant potential barriers to reception and responsive action to the Fellowship. The goal of our Fellowship was to place emphasis on quality assurance and quality improvement activities in the context of scholarship: framing scholarship as a quality assurance practice, with alignment to the broad understanding of scholarship articulated in the Guidance Note.

To achieve this, we contextualised the CER Framework (Kelder \& Carr, 2016, 2017) to suit the STEM discipline. The CER framework embeds scholarship in the cycle of quality improvement (yearly) and quality assurance (external benchmarking; at least 5 yearly) of qualifications, leading to evidence-based scholarly outputs (SoTL) and informing a collaborative approach to curriculum design that can be facilitated within and across disciplines and university boundaries.

Our Fellowship aimed to conceptualise leadership for active engagement in scholarship within teaching teams, which aligns with the Australian Council of Deans of Science (ACDS) theme of 'Building effective leadership for improved learning and teaching' that has its genesis in distributed leadership (Jones \& Harvey, 2017) albeit applied to curricula and quality (Carbone et al., 2017).

In this discussion paper, which is based on our plenary presentation at the Australian Conference for Science and Mathematics Education in 2020, we present our approach to the Fellowship and data on the barriers to engaging in scholarly approaches to teaching. We describe the CER-STEM framework and discuss distributed leadership for implementation of learning and teaching initiatives in the context of education-focused academics. A case study is provided for a College of the University of Tasmania, examining the adoption of the CERSTEM framework in the context of 10 new degrees designed during COVID-19 for delivery in 2020.

\section{Fellowship approach}

Our Fellowship activities were based on the three key steps for successful dissemination outlined in the D-Cubed Guide (Hinton et al., 2011), including: 1) assessing the climate for readiness; 2) consultation and engagement throughout the Fellowship; and 3) enabling transfer of Fellowship outcomes.

The range of resources already developed with Creative Commons attribution to facilitate adoption of the CER framework (Kelder \& Carr, 2017) included an example ethics application; project and research management guidelines; templates e.g., action plans, writing proposals; and an evaluation matrix based on Philips et al. (2012). These were reviewed and tailored for the STEM teaching team context. CER-STEM project web pages were set up on the ACDS Teaching and Learning website (https://www.acds.edu.au/teaching-learning/cer-stem/) to provide ready access to the adapted and revised resources.

Six Colleges/Faculties responsible for Science and allied disciplines (STEM) curriculum were invited to participate in a workshop on the CER-STEM framework, based on an expression of interest. Colleges/Faculties were selected to ensure Universities in each state were represented and the invitation was then extended to other universities in the local area to participate in the workshop, thus broadening the opportunity for academics to engage in fellowship activities. 
Strong interest from universities, the efficient use of resources, and a switch to online delivery of workshops due to COVID-19, meant that we significantly exceeded the planned number of workshops. Twenty workshops were delivered to staff from 14 institutions (Table 1) involving a total of 430 participants.

Table 1. Workshops undertaken as part of the CER-STEM fellowship.

\begin{tabular}{|c|c|c|c|c|}
\hline$\#$ & Institution & Date & Delivery & \# participants \\
\hline 1 & University of New South Wales & Oct 2019 & 1 & 14 \\
\hline 2 & Western Sydney University & Oct 2019 & 1 & 14 \\
\hline 3 & ACSME 'Discipline day' workshop & Oct 2019 & 1 & 15 \\
\hline 4 & Curtin University & Oct 2019 & 1 & 12 \\
\hline 5 & The University of Western Australia & Oct 2019 & 1 & 16 \\
\hline 6 & Murdoch University & Oct 2019 & 1 & 16 \\
\hline 7 & The University of Adelaide & Nov 2019 & 1 & 6 \\
\hline 8 & Federation University Australia & Dec 2019 & 1 & 16 \\
\hline 9 & Deakin University & Dec 2019 & 1 & 15 \\
\hline 10 & La Trobe University & Dec 2019 & 1 & 6 \\
\hline 11 & Swinburne University of Technology & Dec 2019 & 1 & 10 \\
\hline 12 & University of Tasmania & Feb 2020 & 1 & 10 \\
\hline 13 & The University of Melbourne & Jun 2020 & 2 & 5 \\
\hline 14 & University of Newcastle & Jul 2020 & 2 & 6 \\
\hline 15 & The University of Western Australia & Jul 2020 & 2 & 6 \\
\hline 16 & University of Tasmania & Sep 2020 & 2 & 35 \\
\hline 17 & Flinders University & Sep 2020 & 2 & 22 \\
\hline 18 & ACSME Discipline Day Workshop & Oct 2020 & 2 & 8 \\
\hline 19 & La Trobe University & Nov 2020 & 2 & 30 \\
\hline \multirow[t]{2}{*}{20} & ACDS Learning Leader's Webinar & Feb 2021 & 2 & 55 \\
\hline & Total & & & 430 \\
\hline
\end{tabular}

Delivery format: 1 , in person; 2 , online.

Ethics approval for data collection was gained from the University of Tasmania Social Sciences Human Research Ethics Committee before the start of the Fellowship (HREC 18205).

Participants in each workshop (face to face and online) were invited to complete a workshop evaluation. Of 430 participants, 58 completed the evaluation questions. This was helpful for the initial stages of the Fellowship, informing the workshop design, but provided no data on if or how the CER framework was implemented. The questionnaire asked the following questions:

1. How critical do you think it is to respond effectively to the TEQSA guidance note: Scholarship? (5 scale response)

2. How would you rate the scholarly environment for a teaching team you know, according to the TEQSA guidance note: Scholarship? (5 scale response)

3. What are the barriers you see to engaging in scholarship in a teaching team focussed on a STEM curriculum? (Short answer)

4. How confident do you feel that the TEQSA guidance note: Scholarship will be actioned / taken seriously in your discipline / school / faculty / college / institution? (5 scale response)

Results and discussion are presented in the following sections. 


\section{Barriers and opportunities to SoTL}

Workshops were designed to be interactive, and the workshop participants were encouraged to collectively contribute to a whiteboard discussion, identifying perceived barriers to a scholarly environment at their institution, in the context of the STEM disciplines, which were recorded as the discussion progressed.

Most respondents (96\%) to the post-workshop surveys (Table 2) considered it important or very important to respond effectively to the Guidance Note. However, the perceived institutional environment for scholarship to flourish within a teaching team was variable. Many respondents (35\%) rated their scholarly environment in teaching and learning as only 'ok' (on a scale that ranged from 'what scholarly environment?' to 'excellent').

Table 2. Responses to Likert survey questions

\begin{tabular}{|l|c|c|c|c|c|c|}
\hline \multirow{2}{*}{ Question $^{\mathbf{1}}$} & \multicolumn{5}{|c|}{ Rating (\% respondents) $\mathbf{2}^{\mathbf{2}}$} & \multirow{2}{*}{ ( } \\
\cline { 2 - 6 } & $\mathbf{1}$ & $\mathbf{2}$ & $\mathbf{3}$ & $\mathbf{4}$ & $\mathbf{5}$ & \\
\hline Q1: TEQSA guidance note & 0 & 0 & 4 & 39 & 57 & 49 \\
\hline Q2: Scholarly environment & 7 & 21 & 35 & 35 & 2 & 43 \\
\hline Q4: Action & 4 & 8 & 23 & 55 & 10 & 49 \\
\hline
\end{tabular}

${ }^{1}$ Questions are described in full in the Fellowship Approach.

${ }^{2}$ Rating, where 1 is 'what scholarly environment?' (strongly disagree), and 5 is 'excellent' (strongly agree).

Barriers or challenges of STEM academics to engaging in scholarship appear to have experienced little change in the last 10 years. Kelly et al. (2012) reflected that barriers for STEM academics go beyond methodological differences of quantitative versus qualitative approaches, and include time, emotions, intellectual training, and worldviews.

Respondents $(\mathrm{n}=49)$ to our survey $(\mathrm{Q} 3)$ were requested to identify potential barriers to undertaking scholarship from a list. Like Kelley et al. (2012), they identified the main barriers were time allocation and workload issues $(n=23)$, a lack of engagement from academics $(n=$ $15)$ and lack of familiarity in undertaking qualitative research $(n=13)$. For example, three participants stated:

'I think many of my colleagues are interested in engaging scholarship, but people are time poor and prioritise the things that will benefit their career most'

'Recognition nationally and within the school that education research is important and support through appropriate funding / investment.'

'Resources, knowhow to conduct scholarship. Time allocation.'

'Time! Staff don't prioritise L\&T above their science research.'

Despite these comments, a few respondents stated that there was a sense of change in attitudes towards scholarship, consistent with an increase in the number of teaching-focussed staff compared with more traditional teaching and research roles (Ross, 2019), for example: 
'Up to now, it's been time/workload, plus a lack of emphasis on scholarship but, with our new teaching-focussed positions and a strong focus on encouraging and rewarding SoTL, I think this is already changing.'

Our Fellowship, through our engagement with the Australian Council of Deans of Science, advocated that science faculties need to establish a systematic evidence base for the impact of research-informed teaching. Such evidence demonstrates a planned approach to curriculum, which will be audited and monitored by TEQSA.

The design and implementation of quality evaluations that produce objective evidence of outcomes can be regarded as a form of research programs, although of a style more akin to the social sciences than the natural sciences. Our fellowship provides a framework that allows teaching teams in science to adapt to this style of program.

\section{The CER-STEM framework}

The CER-STEM framework (Figure 1) was presented and discussed in workshops as one response to the Guidance Note. There were no substantive changes to the CER-STEM framework resulting from these discussions.

The CER-STEM framework has three interacting components: quality assurance (QA), quality improvement (QI) and scholarship of teaching and learning (SoTL) with a goal of enhancing student learning. The framework is viewed through a quality lens, applies to the whole of a degree and is intended to engage an entire teaching team.

The original CER framework was linear in that QI leveraged QA, which in turn led to scholarly outputs as an endpoint (Kelder \& Carr, 2017). In contrast, QA, QI and SoTL activities in the CER-STEM framework all intersect and interact. For example, and consistent with the Guidance Note, a scholarly approach to teaching informs QI and QA. Alternatively, QA activities may lead to QI and scholarly outputs. As such, the emphasis on any one component of the CER-STEM may vary with the context of institutional strategies or policies, degree life cycle and interests of the teaching team. The CER-STEM framework advocates a collaborative approach, and can be aligned with professional development, peer review, opportunities for leadership, mentoring and career development. 


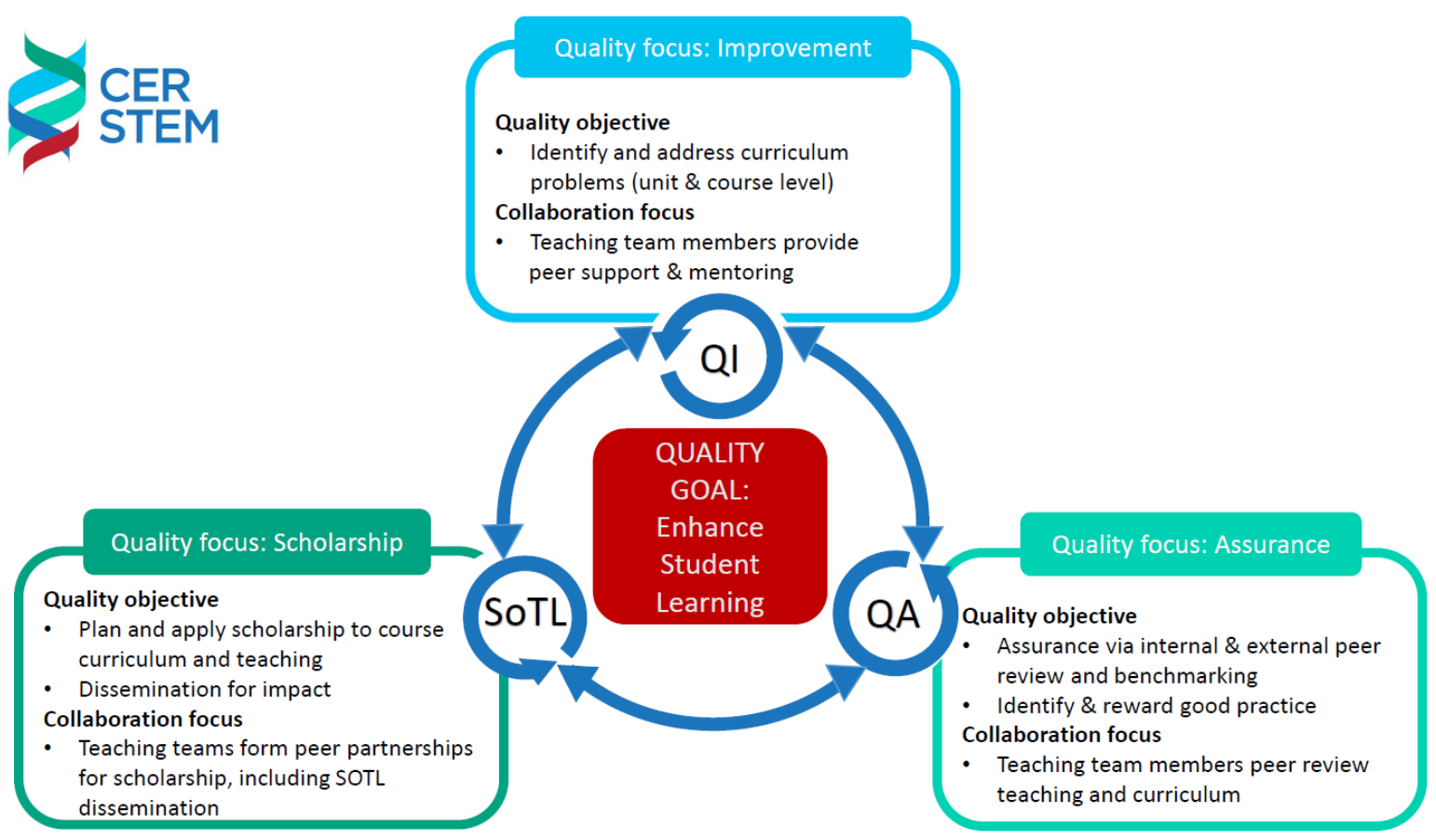

Figure 1. The CER-STEM framework (Acuna \& Kelder, 2021)

\section{Linking and leveraging QA and QI to implement scholarship}

The CER-STEM workshop activities were designed to encourage participants to reconceptualise their approach to scholarship. For example, to think in terms of leveraging existing quality improvement and assurance activities (undertaken through the usual 5-yearly review cycle that is required by TEQSA) and use the same data, building on analysis for QI and QA purposes for scholarship outputs (Figure 2).

The Fellowship also advocated the use of natural data, already generated by participating students and academics, for scholarship. One workshop participant described:

"The presentation completely changed what I understood SoTL to be and broadened it from the very narrow understanding of the term I was operating under. I am now much more confident in articulating my Faculty's responsibilities to undertake and invest in authentic SoTL."

Such an approach necessitates degree-level ethics, so that the procedures for gaining consent to use participants' data complies with the National Statement on Ethical Conduct in Human Research (NHMRC, 2015). At every workshop, participants agreed that applying for ethics approval was a significant barrier to undertaking SoTL, particularly for STEM academics who may be less familiar with qualitative research (Cranton, 2011).

"This workshop has been hugely helpful in suggesting a course-wide approach (instead of subject-only) and also with the generous sharing of resources (especially the awesomely-helpful ethics guide)."

The provision of fellowship resources to apply for ethics and guidance for planning of research during the 5-yearly review cycle, in part address these barriers. 


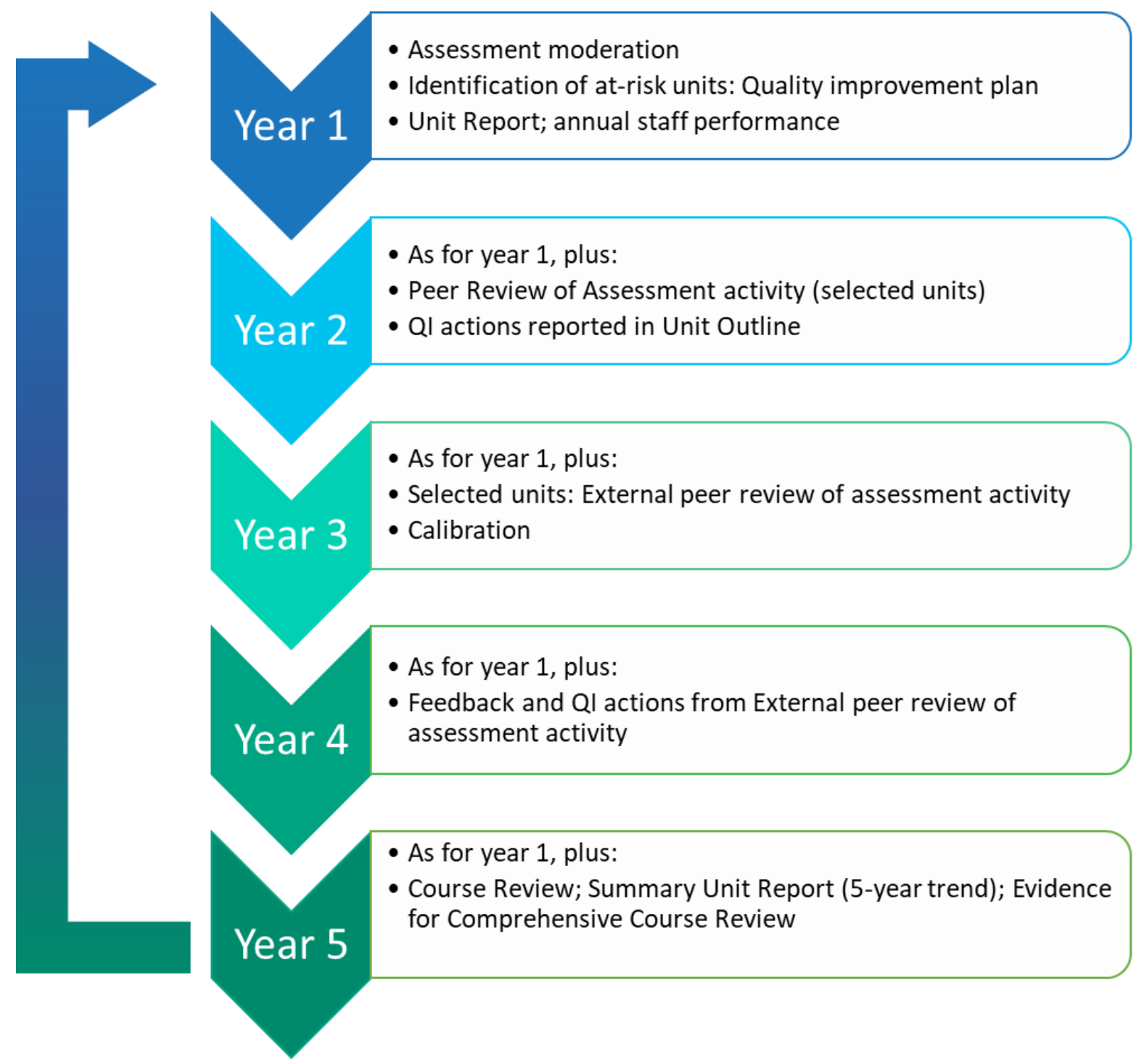

Figure 2. A typical schedule of activities by degree coordinators for compliance with the Higher Education Standards Framework (Acuna \& Kelder, 2021)

COVID-19 affected the conduct and outcomes of the Fellowship. We shifted to online delivery of workshops and conference presentations in mid-2020 and the duration of our Fellowship was extended into 2021. The purpose, core information and supporting resources were warmly received by workshop participants both verbally and in the workshop evaluation responses. In 2020, participants expressed heightened appreciation of the clear value that would be realised had the CER-STEM framework been operationalised before or during the initial stages of COVID-19. The workload of rapid transition to online curriculum delivery meant that academics' capacity to apply the CER-STEM framework to their degree curricula was uniformly minimal.

"While we haven't been able to progress with this as much as we would have liked to this year, it is back on our radar. Being able to take a whole of course approach is going to be invaluable when assessing are learning activities, especially now as have moved so much online." 


\section{Case study: CER-STEM at the University of Tasmania and impact of COVID-19}

At the University of Tasmania (UTAS), as all Australian universities, we planned and executed a transition to online delivery in response to COVID-19. Everyone in the higher education sector (professional support, teacher, unit or degree coordinator, learning and teaching leader) was involved (Crawford et al., 2020). Working from home was the new normal, as was being a few steps ahead of our students in preparing lectures and adapting practicals while rapidly gaining new web conferencing skills.

Compounding this, our university decided to accelerate a planned whole-of-institution academic transformation (University of Tasmania, 2019) of undergraduate degrees, ready for 2021. It was part of a longer-term strategy towards a sustainable future and engendered significant workload. Activities included a review of the course portfolio in each College, and the introduction of new course architectures that provided increased flexibility for students in selecting units. This case study specifically relates to the College of Sciences and Engineering (referred to as 'the college') at UTAS, which reduced its undergraduate programs from 45 to 17 , while the total number of units on offer were approximately halved.

The following quote from Cathy Baldwin encourages us to use our experience of COVID-19 to think deeply about what learning experiences we value for our students and build on this to inform the future of our teaching practices.

"The COVID-19 response is a masterclass in the components of purposeful learningand of using that learning to build an effective quality system - before our very eyes. Let us make them the foundation of our everyday learning and improvement tools now - and when we're talking about the COVID-19 days in the past tense." Dr Cathy Baldwin, Quality Works

This resonates with us, given that the CER-STEM framework is designed to provide a way of approaching quality improvement, quality assurance and scholarship. If not already in place, such an approach could be implemented post COVID-19.

In structuring this case study, we have drawn on the diffusion and adoption principles concepts of Rogers (2003) and impact (Hinton, 2014). Rogers explores diffusion of innovation against five components - relative advantage, compatibility, complexity, trialability and observation. This case study explores compatibility, complexity and considers the role of so-called influencers in the adoption of an innovation.

Adoption and innovation over time typically is represented as a bell curve, where a small proportion of a given population are the early innovators and vice versa those slower to adopt an innovation (Rogers, 2003). We suggest that this adoption trajectory with respect to online delivery was significantly foreshortened - people have described having a day to maybe a week to implement online delivery. Furthermore, it was not just the innovators - it was everyone involved with teaching delivery. Given variation in staff capacity and resources available to implement online delivery on such a timeframe, there was a likely variable impact on the student experience across their degree (Crawford et al., 2020).

We can regard the CER-STEM framework at the UTAS as an innovation, noting that it builds on our existing quality assurance and quality improvement processes. We started with a small 
group of people $(n=10)$ ('innovators') who engaged with a CER-STEM workshop in February 2020. Then COVID-19 happened, so the adoption timeline of the innovation was extended. Now we have new undergraduate curricula that will be rolled out from 2021, so it is timely to adopt the framework, with the target of all the degrees across the College. Unlike our response to COVID-19, this will be a considered process and not done overnight.

Compatibility is defined by Rogers (2003) as the degree to which an innovation is consistent with existing value, past experiences and the needs of potential adopters. At UTAS, our aim was to align the experience of staff in redesigning their curriculum with a need to be able to demonstrate the impact of new curricula on the student experience (Table 3). Implementing the CER-STEM framework can lead to a systematic collection of data about a degree that we can analyse and proactively identify and communicate opportunities for positive change in future - instead of being reactive, as was the case with our response to COVID-19. This approach can lead to, over time, narrow systemic adoption (Hinton et al., 2011) of the CER-STEM framework by the degree team.

Rogers (2003) also describes adoption in terms of the complexity of the innovation (Table 3). One of the mechanisms to enable scholarship arising from quality assurance and quality improvement in the CER-STEM framework is to embed degree-level ethics, for the duration of the degree cycle. However, academics no doubt share the at times, exasperating experience of an ethics application bouncing to and from their social sciences ethics committee during the approval process. Perhaps this is where the experience of teaching focussed academics comes to the fore in leading this type of approach, should they be trained in qualitative approaches. However, not all degree coordinators have this type of background, and ethics can be a huge hurdle. Therefore, our fellowship adapted a range of resources, including ethics templates, to support degree teams to set up the ethics, as was the case at UTAS. In doing so, the fellowship helps to address this potential barrier.

Another aspect explored by Rogers (2003) is the role of the 'influencer', in this case the College, who is responsible for diffusing the innovation (the CER-STEM framework) and influencing its adoption (Table 4). The catalyst was COVID-19, and our new degrees and the need to demonstrate their impact on student learning outcomes and the student experience, as per our College Strategic Plan 2020 - 2025. Also, we have buy-in from the College Leadership Team to implement the CER-STEM framework across a subset of the revised degrees. The College is providing a solution and process - the CER-STEM framework, and resources including a part-time Data Manager to underpin the introduction of the framework.

In summary, the CER-STEM framework was applied to 10 courses in a College of the University of Tasmania. It was applied at the level of degree curriculum and every member of the teaching team for each course was invited to be a participant researcher. The College executive provided funding and workload allocation of an 0.4FTE administrative position which supported tailoring the CER-STEM resources (e.g., the example ethics application) to each course, and continued as data manager for all ten teaching teams/research groups once ethics approval was obtained. This support freed teaching staff to plan evaluation of their course curriculum and scholarship outputs (e.g., publications). The approach has its basis in collecting data once, and using it for multiple purposes, while at the same time meeting the university's quality monitoring requirements. Potential outcomes are the assurance of quality, but with spin offs for publication, team and individual recognition, and to demonstrate impact against college and university strategies for learning and teaching. 
Table 3. Factors influencing the adoption of the CER-STEM (i.e. the 'innovation) framework at UTAS (Rogers, 2003) and subsequent impact (Hinton, 2014).

\begin{tabular}{|l|l|l|l|l|}
\hline \multirow{2}{*}{ Item } & \multicolumn{2}{|l|}{ Degree team } & \multicolumn{2}{l|}{ College } \\
\cline { 2 - 5 } & Description & Impact & Description & Impact \\
\hline Compatibility & $\begin{array}{l}\text { Experience: time } \\
\text { and effort to } \\
\text { design new UG } \\
\text { degrees for 2021; } \\
\text { online delivery in } \\
\text { response to } \\
\text { COVID-19 }\end{array}$ & $\begin{array}{l}\text { Impact on } \\
\text { team } \\
\text { members, } \\
\text { immediate } \\
\text { students }\end{array}$ & $\begin{array}{l}\text { Need: to } \\
\text { demonstrate } \\
\text { impact from the } \\
\text { fellowship, } \\
\text { improve QA }\end{array}$ & $\begin{array}{l}\text { Narrow } \\
\text { systemic } \\
\text { adoption }\end{array}$ \\
\hline Complexity & $\begin{array}{l}\text { Ethics approval } \\
\text { and data } \\
\text { management as } \\
\text { barriers to } \\
\text { adoption }\end{array}$ & & $\begin{array}{l}\text { Large number of } \\
\text { organisational } \\
\text { units and courses }\end{array}$ & \\
& & & \\
& & & \\
\end{tabular}

Table 4. Actions of the College to influence the diffusion and adoption of the CERSTEM framework

\begin{tabular}{|c|c|c|}
\hline Category & Activity & Resource/influence \\
\hline Catalyst & $\begin{array}{l}\text { Pressures the system to } \\
\text { begin working on } \\
\text { 'problems' or issues }\end{array}$ & $\begin{array}{l}\text { New degrees } \\
\text { Strategic impact } \\
\text { College Leadership Team }\end{array}$ \\
\hline Solution giver & $\begin{array}{l}\text { Provides specific idea for } \\
\text { change }\end{array}$ & CER-STEM framework \\
\hline Process helper & $\begin{array}{l}\text { Assists in the processes of } \\
\text { problem solving and } \\
\text { decision making }\end{array}$ & $\begin{array}{l}\text { CER-STEM framework } \\
\text { resources, including ethics } \\
\text { templates aligned with the } \\
\text { National Statement }\end{array}$ \\
\hline Resource linker & $\begin{array}{l}\text { Brings together human, } \\
\text { economic and intellectual } \\
\text { resources }\end{array}$ & $\begin{array}{l}\text { People and expertise } \\
\text { provided by College and the } \\
\text { university learning and } \\
\text { teaching unit }\end{array}$ \\
\hline
\end{tabular}

\section{Distributed leadership and CER-STEM}

Leadership in higher education includes both positional and distributed leadership. When we first conceived our fellowship, we regarded distributed leadership as central to the implementation of the CER-STEM framework. Jones and Harvey (2017) and Carbone et al. (2017) discuss that a distributed leadership approach can create impact through building leadership capacity and engaging people in collaborative practices (Table 5). With regards to curricula and student learning, this has been demonstrated in individual peer assessment of teachers (Carbone, 2015) and now for teaching teams, through the CER-STEM framework. 
Education-focused roles have increased dramatically in the academic workforce over the last decade and Ross (2019) identified a number of emergent themes regarding academic roles in science. Education-focused academics have raised issues such as, but not limited to, scholarship, funding, progress and promotion, and research. Distributed leadership in the implementation of the CER-STEM framework can provide opportunity for education-focused academics to demonstrate leadership in scholarship and mentoring of other staff.

The literature on distributed leadership highlights that local teams still need managerial support with regards to workload, resources, recognition and reward (Carbone, 2015; Jones \& Harvey, 2017). Deans and Academic Deans have the responsibility for creating an institutional environment to support CER-STEM activities, otherwise workload becomes an overwhelming barrier to distributed leadership.

Table 5. Distributed leadership and CER-STEM

\begin{tabular}{ll}
\hline Criteria for Distributed Leadership & CER-STEM framework \\
\hline People are involved & Whole of teaching team, professional staff, students \\
Processes are supportive & $\begin{array}{l}\text { Invitational, collaborative, peer partnerships, focus on } \\
\text { curriculum and students' learning, recognition and } \\
\text { rewards }\end{array}$ \\
Professional development is provided & $\begin{array}{l}\text { Peer mentoring, peer partnerships, invited expert } \\
\text { presentations, collaborative learning }\end{array}$ \\
Resources are available & $\begin{array}{l}\text { Data manager, workload allocation } \\
\text { Use and adapt CER-STEM resources } \\
\text { Develop own resources }\end{array}$ \\
\hline
\end{tabular}

Adapted from Jones and Harvey (2017)

\section{Conclusion}

There is increasing demand for assurance of quality in relation to teaching and learning in higher education. Never has this been more relevant than in response to COVID-19, with the rapid shift to online delivery. It is yet to unfold how this may impact our future teaching practice. It does emphasise the need for our teaching practice and evaluation to be agile. Furthermore, funding of teaching is changing; not just performance funding, but the requirements from TEQSA, whether this be guidance notes, or the HESF more generally.

This raises several challenges and/or opportunities. We need to monitor the impact of changes holistically and systematically to our degrees/majors and units on the learning experience and outcomes of our students. If data collection and analysis is piecemeal or ad-hoc, we cannot link strategies intended to improve quality with the assurance of quality and student outcomes. As described by one workshop participant:

"I think that there will be longer term benefits to student learning in STEM through the design and development of evidence-based learning experience and teaching \& assessment practice." 
In response, we advocate the adoption of the CER-STEM framework as one approach to how we organise our quality improvement, quality assurance and scholarship, which can be locally contextualised, but builds on existing processes in a rigorous way that provides evidence to inform a range of decisions about learning and teaching resourcing and strategy. However, successful adoption requires distributed leadership and institutional support. Finally, we advocate the continued existence of fellowship schemes and funding opportunities. These provide a focal point for communities of practice in learning and teaching that can benefit everyone, with the aim of leading to improved outcomes for our students.

Post-pandemic, fundamental questions are: How has the online delivery and associated accommodations to assessment impacted the quality of our teaching and learning? How will this be reflected in institutional and national quality indicators? How have the expectations of our students changed?

\section{Acknowledgements}

We gratefully acknowledge the support of the Australian Council of Deans of Science for our joint Fellowship, and to our mentors Professors Cristina Varsavsky, John Rice and Susan Jones.

\section{References}

Acuna, T., \& Kelder, J-A. (2021). CER-STEM. Australian Council of Deans of Science. Retrieved August 3, 2021, from https://www.acds.edu.au/teaching-learning/cer-stem/

Carbone, A. (2015). Developing excellence in learning and teaching through a Peer Assisted Teaching Scheme. Final report. Office for Learning and Teaching. Retrieved August 3, 2021, from https://altf.org/wpcontent/uploads/2016/08/Carbone_A_NSTF_Final-report.pdf. https://doi.org/10.1080/1360080X.2017.1276629

Carbone, A., Evans, J., Ross, B., Drew, S., Phelan, L., Lindsay, K., Cottman, C., Stoney, S., \& Ye, J. (2017). Assessing distributed leadership for learning and teaching quality: A multi-institutional study. Journal of Higher Education Policy and Management, 39(2), 183-196. https://doi.org/https://doi.org/10.1080/1360080X.2017.1276629

Cranton, P. (2011). A transformative perspective on the Scholarship of Teaching and Learning. Higher Education Research \& Development, 30(1), 75-86. https://doi.org/10.1080/07294360.2011.536974

Crawford, J., Butler-Henderson, K., Jurgen, R., Malkawi, B. H., Glowatz, M., Burton, R., Magni, P., \& Lam, S. (2020). COVID-19: 20 countries' higher education intra-period digital pedagogy responses. Journal of Applied Learning \& Teaching, 3. https://doi.org/10.37074/jalt.2020.3.1.7

Hinton, T. (2014). The Impact Management Planning and Evaluation Ladder (IMPEL). Office for Learning and Teaching.https://www.dese.gov.au/download/3259/impact-management-planning-and-evaluation-ladderimpel/4667/document/docx.

Hinton, T., Gannaway, D., Berry, B., \& Moore, K. (2011). The D-cubed guide: Planning for effective dissemination. Australian Teaching and Learning Council. Retrieved August 3, 2021, from https://www.uq.edu.au/evaluationstedi/Dissemination/Planning_Guide.pdf

Jones, S., \& Harvey, M. (2017). A distributed leadership change process model for higher education. Journal of Higher Education Policy and Management, 39(2), 126-139. https://doi.org/https://doi.org/10.1080/1360080X.2017.1276661

Kelder, J., \& Carr , A. (2016). Workshop: Embedding evaluation and research into curriculum design and delivery.The Shape of Higher Education, Freemantle, WA: HERDSA

Kelder, J., \& Carr , A. (2017). Embeddingevaluation and scholarship into curriculum and teaching: The Curriculum Evaluation Research framework. In A. Hørsted, A. Bartholomew, J. Branch, \& C. Nygaard (Eds.), New Innovations in Teaching and Learning in Higher Education. (pp. 451-471). United Kingdom: Libri Publishing.

Kelly, N., Nesbit, S., \& Oliver, C. (2012). A difficult journey: Transitioning from STEM to SoTL. International Journal for the Scholarship of Teaching and Learning, 6(1). https://doi.org/https://doi.org/10.20429/ijsotl.2012.060118

NHMRC. (2015). National Statement on Ethical Conduct in Human Research (2007). Updated 2015. https://www.nhmrc.gov.au/research-policy/ethics/national-statement-ethical-conduct-human-research

Philips, R., McNaught, C., \& Kennedy, G. (2012). Evaluating e-learning: Guiding research and practice. New York: Routledge. https://doi.org/10.4324/9780203813362

Rogers, E. (2003). Diffusion of Innovations (5th ed.). New York: Free Press. 
Ross, P. (2019). The changing nature of the academic role in science. Final report. Australian Government Department of Education. Retrieved August 3, 2021 from https://altf.org/wpcontent/uploads/2017/06/FS14-0232_Ross_FinalReport_2019.pdf

TEQSA. (2018). Guidance Note - Scholarship. Retrieved December 4, 2018 from https://www.teqsa.gov.au/latest-news/publications/guidance-note-scholarship

University of Tasmania. (2019). University of Tasmania Strategic Plan: 2019 - 2024. University of Tasmania. 